\title{
Design and use of a U.S. census data computer laboratory for teaching undergraduate research methods
}

\author{
M. ANN DRAKE and JEANNE M. STAHL \\ Morris Brown College, Atlanta, Georgia
}

\begin{abstract}
This paper discusses the design and development of an interdisciplinary social science computer laboratory for teaching undergraduate research methods courses and research components of applied and theoretical courses. The U.S. Census of the Population, a database commonly used in all of the social sciences, is used in order to give students research experience and to avoid ethical problems involved in working with animal and human subjects in an undergraduate course. Some issues in laboratory design and required changes in teaching methods are discussed.
\end{abstract}

Recent examinations of undergraduate education in psychology (Greene, 1991; McGovern, 1993) and other disciplines (American Association of Community and Junior Colleges, 1988) have pointed out the need to address diversity in learning styles and educational background and have recommended restructuring the learning environment to stimulate active learning. Historically, the social sciences have had a strong tradition of "hands-on" learning in both the laboratory and the field. However, it is difficult at some small colleges to continue this tradition because it is too costly, classes are too large, and faculty, who teach four or five different courses per semester, are pressed for time.

Even for colleges with adequate resources, ethical conflicts may develop, involving the protection of human and animal subjects in undergraduate research courses (Herzog, 1990). In some situations, it is not possible for faculty who are teaching research methods courses to gain approval from an institutional review board in time for student projects to be completed within a semester.

At Morris Brown College, we have experienced all of these problems. Morris Brown College is a member of the Atlanta University Center, the largest consortium of historically black colleges and universities in the world. It is a small, church-related, undergraduate college with a total enrollment of 1,900 students. Approximately $22 \%$ of these students major in the social sciences.

Until recently, social science majors did not have access to microcomputers in a laboratory classroom. This paper describes the development of a networked computer classroom designed for teaching core research methods courses in the social sciences using the U.S. Census of the Population as a research database. The lab-

This work was supported in part by a grant from the U.S. Department of Education, Minority Science Improvement Program (P120A30094-94). Correspondence concerning this article should be addressed to M. A. Drake, Department of Social Science, Morris Brown College, 643 M. L. King, Jr. Drive, Atlanta, GA 30314. oratory is designed so that all of the social science classes that include research components, both applied and theoretical, are able to use the facility to meet the following instructional aims:

1 . The development of students' critical thinking skills, including the organization of materials, development of relationships, and conceptualizing and reasoning about theoretical and statistical information. Persell (1992) gives several examples indicating that computers may be an invaluable tool for teaching these skills.

2 . The development of research skills, including the ability to conduct appropriate literature searches, collect and organize data, select appropriate variables, and use statistical tests.

3. The development of writing skills, including presentation, organization, grammar, spelling, and sentence structure. The computer laboratory makes it possible for students to write multiple drafts of their material and receive immediate feedback from their instructors.

4. The development of computer skills, including word processing, database, graphics, spreadsheet, and statistical software programs.

5. The development of statistical skills, including work with databases that are commonly used in research and in agencies addressing issues found in the social sciences.

\section{COMPUTER LABORATORY}

\section{Design of the Laboratory}

The laboratory consists of 24 computer stations on a Token Ring network topology located in a classroom with connections to two faculty offices. This network is connected to a larger fiber optic network that has at least one other networked classroom on it. There are additional connections to the system in the Learning Resource Center which provide students a place to work on the network outside of class.

The server, a Hewlett-Packard Netserver LE 4/33-DX (1GB) and CD-ROM (an NEC CDR-84-1), which is in- 
ternal to the server, are located in the office of the director for security and administrative purposes. A Colorado Powertape backup system is installed in the director's office. The workstations are IBM-compatible Hewlett-Packard 486/25 SX computers with $8 \mathrm{Mb}$ of RAM and $120-\mathrm{Mb}$ hard drives. Two dot matrix printers (Epson LQ 570) and one wide-carriage (Epson LQ 1170) printer are located in the laboratory for students and general faculty use.

\section{Laboratory Management}

Students are assigned independent accounts on the network that are inaccessible to anyone except the network supervisor. Each student is given a login name by the network supervisor and is required to select a unique password.

A system of logical drives has been developed to facilitate the functioning of the laboratory. Drives that are accessible to faculty and students include the A drive, (the 3.5-in, floppy disk drive on the computer), and logical drives $\mathrm{I}, \mathrm{L}$, and $\mathrm{H}$ on the server. Each user has a unique logical $\mathrm{H}$ drive or "home directory" that is inaccessible to other users. The logical L drive, or "learning drive," is used by faculty to give student assignments and examinations. Students have read-only privileges in this drive. They must save any of their work in the logical $\mathrm{L}$ drive to the $\mathrm{H}, \mathrm{I}$, or A logical drives. The logical drive I, or "instructors' drive," is used by faculty for the purposes of grading and commenting on students' work. Students may save only to this drive, and once they have saved their work, they no longer have access to it.

Each night, material that has been loaded on the server is backed up on the tape drive. This is an added security measure to help protect faculty and students from loss of their work as well as to maintain data and software on the system.

Students enrolled in the courses taught in the laboratory are required to perform their work on the network and to save their material on the $\mathrm{H}, \mathrm{I}$, and A drives. This method of saving allows the students the opportunity to work on stations that are not on the network and at the same time give the instructors access to student work for purposes of grading and commenting on works in progress.

Students and faculty on the network are not given access to the hard drives of the individual computers or what we traditionally think of as the $\mathrm{C}$ drive. This measure is taken as a protection against viruses, and more importantly, as a means of simplifying the administration of the network. Before retrieving material on a floppy disk, users are required to check the disk for viruses by using the antivirus software.

Restricting access to these four logical drives means that all software and data may be loaded from a single account onto the entire network without going to each individual workstation to accomplish this purpose. The director's account has network supervisor privileges. Student and faculty account problems may be resolved by a network supervisor from any workstation on the network. It also means that rather than having to use the same workstation to conduct their work, student and faculty may access the system from any workstation on the network through their individual accounts.

Student accounts automatically become disabled at the end of the semester. If students are to continue to work in the laboratory, they must create a new account the next semester. Faculty members' accounts require that they change their passwords every 6 months. These measures are taken in order to keep the user accounts current and to control access to the system in an orderly and equitable fashion.

\section{Software in Use}

Because the following software packages are widely used in both graduate schools and in public and private agencies, special emphasis has been placed on them: SPSS; Lotus 1,2,3; Harvard Graphics; Microsoft Word; WordPerfect; and Borland Paradox (a database software program for processing many data banks). Other software packages developed for specific courses, such as Microcase Criminology, Experimental Psychology Simulations, and PCGlobe, will be added as their usefulness is determined. Central Point Antivirus for networks, Intel LANSpool software for NetWare, DOS, Windows, and Novell Netware are all necessary for the operation of some or all of the programs on the system.

\section{A Database Common to the Social Sciences}

The U.S. Census of the Population, which is on CDROM, is a database that is used by a variety of public agencies for purposes as varied as the definition of representative jurisdictions and the funding of hospitals and social programs. The database currently installed includes the 1990 counts for the United States and for the states of Georgia and Florida. These data sets provide students and faculty access to tables that have already been developed on information about housing, income, occupation, race and ethnic identity, sex, age, family structure and marital status, household type, educational achievement, and economic status. The geographic levels of analysis for these data are national, state, regional, county, urban, and nonurban areas, and include census tract and block level information for urban areas.

PUMPS (CD 90-PUMPSA1) is a subset of the census based on the $5 \%$ sample of raw data that can be used by students so that they can define their own statistical tests.

\section{LABORATORY CLASSROOM ACTIVITIES}

\section{Core Courses}

The lab is a general social science facility used by faculty and students in psychology, criminal justice, sociology, political science, paralegal studies, religion, philosophy, African-American studies, and history. Students in these majors are required to take the following courses, which are taught in the computer laboratory: advanced courses in technical writing, research methods, statistics, and com- 
puter science. They are also required to take an exit research seminar that makes use of their writing, statistical, reading, and technical skills on the computer.

\section{Examples of Classroom Activities}

The research seminar course, which is taught in the computer laboratory, addresses the instructional aims in the present project, including critical thinking, research, writing, statistics, and computer technological skills. The data for census tracts for one or two neighborhoods are selected. Students are given a choice of three or four research topics, such as educational achievement, occupation, poverty, or quality of mental health care. They are required to conduct a literature search on their proposed topic of interest and then to narrow the focus of their search. For example, students may decide to address the issue of poverty from the perspective of race, sex, education, or occupation. They identify key variables, which they analyze in their treatment of the census data for their assigned community. They are to analyze and write about the theoretical and social policy issues relating to their problem and to present their findings in an organized and well-thought-out section of their paper. They then develop a profile for their assigned community, based on the census data. This profile includes the selection of appropriate variables which they will consider in their research. They will develop graphs, maps, and tables on the basis of these data. They will also conduct statistical tests such as chi-square, $t$ test, and Pearson's $R$, when appropriate.

Working on the census data in a laboratory setting provides students with an opportunity to discuss their research findings with their instructor while they work with the data bank. This encourages the students to define a research topic, think through their findings, and, hence, develop critical thinking skills.

Students develop their writing skills because they are using the word processor during every class period to take notes, write about their research findings, and record the demographic qualities of their neighborhoods. They develop their statistical skills as they analyze the data from the U.S. Census data bank. In the process, they gain technical skills by using the software in the laboratory.

Student responses to the use of the computer laboratory as a teaching environment are positive. They demonstrate through their writing and their use of statistical methods that the use of computerized education is an important tool in their achievement.

\section{PROBLEMS ENCOUNTERED}

Persons designing a computer laboratory for the first time may encounter some of the same problems that we encountered.

1. It is important to review your proposed design and equipment specification after funding is received. The design and capabilities of computers, the programming of software, and their costs change rapidly. Such changes will occur between the time that a proposal is submitted and funding is made available. For instance, 2 years ago $4 \mathrm{Mb}$ of RAM was considered adequate for most software. Today people are routinely buying 16 and $24 \mathrm{Mb}$ of RAM.

2 . The demand for the use of the facilities for computerbased education is far greater than anticipated. The solution to this problem is to be found in the development of a small networked laboratory, located in a central area of the college, connected to all of the classroom networks. This enables students to work on their out-of-class assignments in accordance with their schedules.

3. A third difficulty is the "computer phobia" of some students and faculty. These problems persist and make demands on an instructor's time both in and out of class. One way of addressing this problem is to have weaker students work with more experienced ones. A second approach is to employ a lab technician who is proficient in several software programs and in the use of networks. This person must be knowledgeable, patient, and comfortable in working with both faculty and students.

4. Because it takes several class sessions to introduce students to the use of the standard software programs, students are encouraged to take computer science courses prior to enrolling in advanced methods courses.

5. Faculty who use the laboratory in their teaching must address the issue of changing teaching styles (Baldwin, 1984; Belker, 1985; Gibbons, Fairweather, \& O'Neal, 1993; Katz, 1992). Lectures may take a secondary role while students learn through using computer technology.

6. As others have reported (Greene, 1991; Hazari, 1991), few faculty have experience with microcomputers on networks. A series of training workshops was therefore instituted, consisting of instruction in how to access and use the network drives, Windows, WordPerfect, SPSS, and the census data. The laboratory technician is available to work with faculty members on the technical problems in the development of the courses and the uses of their software. Faculty network users then develop course syllabi and class exercises incorporating the use of computers and the census data. This information is shared in summer and midyear faculty workshops.

\section{FINDINGS}

It is apparent that the use of the U.S. Census data in teaching both statistics and writing research papers requires that students become involved in the learning process. Students also appreciate the attention given to them in the informal environment found in a laboratory.

However, this means that instructors must be more focused and provide structured assignments. Students must conduct research covering material which would normally be given in class lectures. Clear boundaries and expectations of content mastery must be assigned and examined.

\section{REFERENCES}

American Association of Community and Junior Colleges. (1988). Building communities: $A$ vision for a new century. Washington, DC: Author. 
BALDWIN, R. G. (1984). The changing development needs of an aging professorate. In C. M. N. Mehotra (Ed.), Teaching and aging (pp. 4556). San Francisco: Jossey-Bass.

BELKER, J. S. (1985). The education of mid-career professors: Is it continuing? College Teaching, 33, 68-71.

GibBons, A. S., Fairweather, P. G., \& O'Neal, A. F. (1993). The future of computer-managed instruction (CMI). Educational Technology, 33(5), 7-11.

GrEenE, B. B. (1991). A survey of computer integration into college courses. Educational Technology, 31, 37-47.

HAZARI, S. (1991). Microcomputer training for higher education faculty. Educational Technology, 31, 48-50.

HeRzoG, H. A. (1990). Discussing animal rights and animal research in the classroom. Teaching of Psychology, 17(2), 90-94.
KATZ, Y. J. (1992). Toward a personality profile of a successful computer-using teacher. Educational Technology, 32, 39-41.

MCGovern, T. V. (Ed.) (1993). Handbook for enhancing undergraduate education in psychology. Washington, DC: American Psychological Association.

Persell, C. H. (1992). Bringing PCS into introductory sociology courses: First steps, missteps, and future prospects. Teaching Sociology, 20, 91-103.

(Manuscript received November 29, 1994;

revision accepted for publication February 6, 1995.) 